respiratory tract infections were the most common TEAEs, with no dose response (Table 1). Tracheobronchitis and pneumonia, were mild to moderate severity, not associated with absolute neutrophil count G3, and none led to treatment withdrawal.

At Wk 52, efficacy was sustained for pts who continued $300 \mathrm{mg}$ in TP2 (ESSDAI, ESSPRI, PaGA, PhGA CHB: -9.06, -1.91, -22.03, -35.80, respectively). Efficacy was partially lost for pts switched to PBO at Wk 24 (Figure 1). Improvement was noted for PBO pts switched to $150 \mathrm{mg}$. Stimulated whole salivary flow at Wk 24 was improved for $300 \mathrm{mg}$ (PBO-adjusted $\mathrm{CHB} 0.20 \mathrm{ml} / \mathrm{min}$; $\mathrm{P}=0.037$ ); last measurement at Wk 48 was 0.45 and $0.22 \mathrm{ml} / \mathrm{min} \mathrm{CHB}$ in pts who continued $300 \mathrm{mg}$ or PBO in TP2, respectively.

Conclusion: lanalumab $300 \mathrm{mg}$ was well tolerated up to $52 \mathrm{Wks}$. Exploratory efficacy showed that continuous dosing of $300 \mathrm{mg}$ s.c. q4w provided sustained clinical benefit. PaGA was the outcome that showed the most prominent change following switch to PBO or VAY736.

REFERENCES:

[1] Dörner T, et al. [OP0302]. Ann Rheum Dis. 2020; 79 (suppl 1).

Table 1. Key Safety Data (All Study Periods up to Week 52)

\begin{tabular}{|c|c|c|c|c|}
\hline n (\%) & $5 \mathrm{mg}$ & $50 \mathrm{mg}$ & $150 \mathrm{mg}$ & Any $300 \mathrm{mg}(\mathrm{N}=47)$ \\
\hline \multirow[t]{2}{*}{ 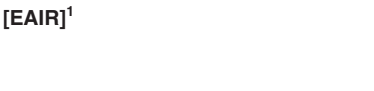 } & 24 Wks & 24 Wks & 28 Wks & \\
\hline & $(\mathrm{N}=47)$ & $(\mathrm{N}=47)$ & $(\mathrm{N}=47)$ & \\
\hline \multirow[t]{2}{*}{ Any AE } & $43(91.5)$ & $43(91.5)$ & $44(93.6)$ & $45(95.7)$ \\
\hline & [517.5] & [423.3] & [621.0] & [544.6] \\
\hline \multirow[t]{2}{*}{ Any SAE } & $3(6.4)$ & 5 (10.6) & $8(17.0)$ & $8(17.0)$ \\
\hline & [5.9] & [10.7] & [19.9] & [13.6] \\
\hline \multirow[t]{2}{*}{ Infections and infestations (SOC) ${ }^{2}$} & $33(70.2)$ & $31(66.0)$ & $34(72.3)$ & $38(80.9)$ \\
\hline & [154.1] & [119.2] & [162.0] & [127.7] \\
\hline Nasopharyngitis $^{3}$ & $7[15.5]$ & $4[8.5]$ & 9 [22.1] & $9[16.5]$ \\
\hline Upper respiratory tract infections ${ }^{3}$ & $6[12.8]$ & $8[17.8]$ & $5[11.6]$ & $8[13.6]$ \\
\hline Bronchitis $^{3}$ & $3[6.2]$ & $3[6.2]$ & $4[9.5]$ & $4[6.6]$ \\
\hline Tracheobronchitis $^{3}$ & $1[2.0]$ & $0[0.0]$ & $0[0.0]$ & $3[5.0]$ \\
\hline Pneumonia $^{3}$ & $1[2.0]$ & $0[0.0]$ & 1 [2.2] & 2 [3.3] \\
\hline \multirow[t]{2}{*}{ Blood \& Lymphatic Disorders (SOC) ${ }^{2}$} & $8(17.0)$ & $9(19.1)$ & $6(12.8)$ & $9(19.1)$ \\
\hline & [18.0] & [20.8] & [14.3] & [16.8] \\
\hline Lymphopenia $^{3}$ & $4[8.4]$ & $4[8.6]$ & $3[6.8]$ & $2[3.3]$ \\
\hline Neutropenia $^{3}$ & $5[10.7]$ & $1[2.1]$ & $2[4.5]$ & 4 [6.9] \\
\hline Injection site reaction ${ }^{3}$ & $4(8.5)$ & $9(19.1)$ & $17(36.2)$ & $27(57.4)$ \\
\hline
\end{tabular}

*Includes all safety data from TP1, TP2 and post-treatment follow-up; cut-off 06-Feb$2020^{1}$ EAIR, incidence rate per 100 subject years. For patient with an event, exposure time is censored at time of first event; ${ }^{2}$ Number of pts with at least one $A E$ in $S O C ;{ }^{3} \mathrm{PT}$, preferred term;SOC, system organ class

Figure: Summary of Efficacy data at Week 52 (Treatment Period from Wk 24 to Wk 52)

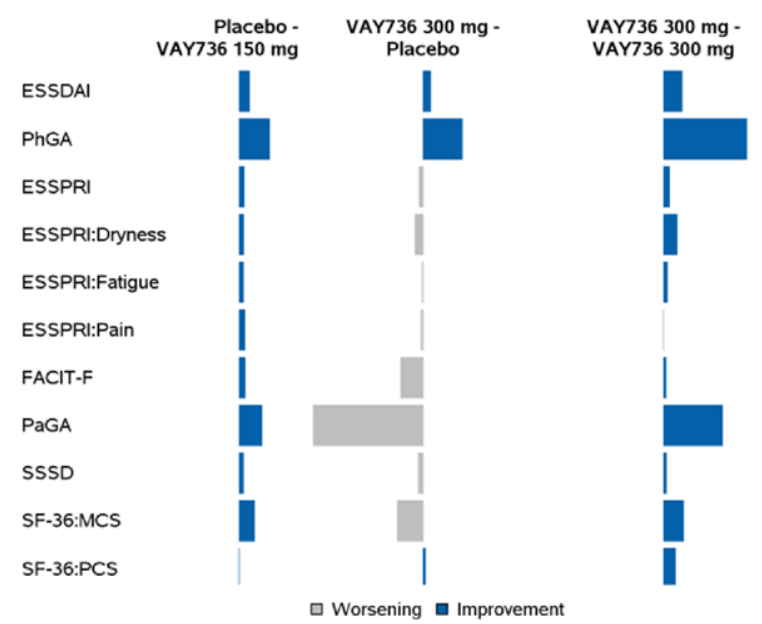

ESSDAI, EULAR Sjögren's Syndrome Disease Activity index; ESSPRI, EULAR Sjogren's Syndrome Patient Reported Index, EULAR, European League Against Rheumatism; FACIT-F, Functional Assessment Patient Reported Tex, EULAR, European League Aganst Ric PCS, physical syndrome symptom diary

Disclosure of Interests: Thomas Dörner Consultant of: Novartis, GSK, Sanofi, Janssen, Eli Lilly, Grant/research support from: Deutsche Forschungsgemeinschaft, Simon J. Bowman Consultant of: Astrazeneca, Biogen, BMS, Celgene, Medimmune, MTPharma, Novartis, Ono, UCB, xtlbio, Robert Fox
Consultant of: Novartis, Pfizer and Lilly, Xavier Mariette Consultant of: BMS, Galapagos, Gilead, Medimmune, GSK, Grant/research support from: Servier, Athena Papas Consultant of: Novartis, Grant/research support from: Novartis, Thomas Grader-Beck Consultant of: Novartis, Lilly, Grant/research support from: Abbvie, Celgene, Ben A Fisher Consultant of: Novartis, Roche BMS and Servier, Filipe Barcelos Consultant of: Pfizer and Lilly, Salvatore De Vita Consultant of: Roche, Human Genome Science, Glaxo Smith Kline and Novartis, Hendrik Schulze-Koops Consultant of: Novartis, Robert J Moots Consultant of: Amgen, Chugai, Gilead, Lilly, Novartis, Pfizer, Roche, Grant/research support from: Amgen, Chugai, Gilead, Lilly, Novartis, Pfizer, Roche, Guido Junge Shareholder of: Novartis, Employee of: Novartis, Janice Woznicki Shareholder of: Novartis, Employee of: Novartis, Monika Sopala Shareholder of: Novartis, Employee of: Novartis, Wen-Lin Luo Shareholder of: Novartis, Employee of: Novartis, Wolfgang Hueber Shareholder of: Novartis, Employee of: Novartis

DOI: 10.1136/annrheumdis-2021-eular.1700

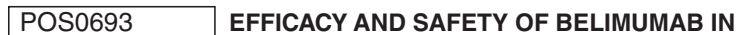 PATIENTS WITH LUPUS NEPHRITIS IN REAL-LIFE SETTING: RESULTS FROM A LARGE, NATIONWIDE, MULTICENTRIC, PROSPECTIVE COHORT}

F. Saccon ${ }^{1}$, M. Gatto ${ }^{2}$, M. Zen ${ }^{2}$, M. Fredi ${ }^{3}$, F. Regola ${ }^{3}$, F. Franceschini ${ }^{3}$, A. Tincani ${ }^{3}$, G. Emmi ${ }^{4}$, F. Ceccarelli ${ }^{5}$, F. Conti ${ }^{5}$, A. Bortoluzzi ${ }^{6}$, M. Govoni ${ }^{6}$,

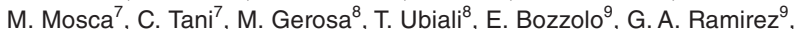
L. Moroni ${ }^{9}$, A. Gabrielli ${ }^{10}$, P. Cardinaletti ${ }^{10}$, E. Gremese ${ }^{11}$, G. Tanti ${ }^{12}$, S. De Vita $^{13}$, G. De Marchi ${ }^{13}$, S. Fasano ${ }^{14}$, F. Ciccia $^{14}$, G. Pazzola ${ }^{15}$, C. Salvarani ${ }^{15}$, G. Orsolini ${ }^{16}$, M. Rossini ${ }^{16}$, P. Faggioli ${ }^{17}$, A. Laria $^{18}$, S. Scarpato ${ }^{19}$, A. De Paulis $^{20}$, E. Brunetta ${ }^{21}$, E. Bartoloni Bocci ${ }^{22}$, R. Gerli ${ }^{22}$, F. Benvenuti ${ }^{1}$, L. laccarino ${ }^{2}, A$. Doria ${ }^{2}$ on behalf of BeRLiSS Study Group. ${ }^{1}$ University of Padua, Division of Rheumatology, Department of Medicine DIMED, Padua, Italy; ${ }^{1}$ University of Padua, Division of Rheumatology, Department of Medicine DIMED, Padua, Italy; ${ }^{3}$ ASST Spedali Civili di Brescia, Department of Clinical and Experimental Sciences, Brescia, Italy; ${ }^{4}$ University of Firenze, Department of Experimental and Clinical Medicine, Firenze, Italy; ${ }^{5}$ Sapienza University of Roma, Dipartimento Universitario di Scienze Cliniche, Internistiche, Anestesiologiche e Cardiovascolari (SCIAC), Rome, Italy; ${ }^{6}$ University of Ferrara, Rheumatology Unit, Ferrara, Italy; ${ }^{7}$ University of Pisa, Rheumatology, Pisa, Italy; ${ }^{8}$ Milan ASST Gaetano Pini, Department of Clinical Sciences and Community Health, Milan, Italy; ${ }^{9}$ Milan San Raffele, Medicina Generale e delle Cure Avanzate, Milan, Italy; ${ }^{10}$ Università Politecnica delle Marche, Dipartimento di Scienze Cliniche e Molecolari, Ancona, Italy; ${ }^{11}$ Rome Fondazione Policlinico Universitario A. Gemelli-IRCCS, Division of Rheumatology, Rome, Italy; ${ }^{12}$ Università Cattolica del Sacro Cuore Sede di Roma, Division of Rheumatology, Rome, Italy; ${ }^{13}$ University of Udine, Rheumatology Unit, Udine, Italy; ${ }^{14}$ Università degli Studi della Campania Luigi Vanvitelli, Deparment of Precision Medicine, Naples, Italy; ${ }^{15}$ Reggio Emilia, Division of Rheumatology, Reggio Emilia, Italy; ${ }^{16}$ University of di Verona, Unit of Rheumatology, Verona, Italy; ${ }^{17}$ ASST OVEST Milanese presidio di Legnano, Rheumatology Unit, Legnano, Italy; ${ }^{18}$ ASST OVEST Milanese presidio di Magenta, Division of Rheumatology, Magenta, Italy; ${ }^{19}$ Salerno Ospedale M. Scarlato, Rheumatology, Salerno, Italy; ${ }^{20}$ University of Napoli Federico II, Dipartimento di Scienze Mediche Traslazionali e Centro di Ricerca Immunologia Base e Clinica (CISI), Naples, Italy; ${ }^{21}$ Istituto Clinico Humanitas, Rheumatology, Milan, Italy; ${ }^{22}$ University of Perugia, Department of Medicine, Perugia, Italy

Background: $L N$ is still a severe manifestation of Systemic lupus erythematosus (SLE) and multitarget therapy is needed to control the disease especially in refractory cases.

Objectives: To evaluate renal response in SLE patients with glomerulonephritis (GN) treated with Belimumab in real-life setting.

Methods: Patients with proteinuria $>0.5 \mathrm{~g} / 24 \mathrm{~h}$ and/or active sediment at baseline enrolled in a multicentre Italian cohort of SLE patients (BeRLiSS study), treated with monthly iv Belimumab $10 \mathrm{mg} / \mathrm{kg}$ plus standard of care were considered in this study. Complete renal response (CRR) was defined as proteinuria $<0.5 \mathrm{~g} / 24 \mathrm{~h}$, estimated glomerular filtration rate (eGFR) $\geq 90 \mathrm{ml} / \mathrm{min} / 1.73 \mathrm{~m}^{2}$ and no rescue therapy. Primary efficacy renal response (PERR) was defined as proteinuria $\leq 0.7 \mathrm{~g} / 24 \mathrm{~h}$, eGFR $\geq 60 \mathrm{ml} / \mathrm{min} / 1.73 \mathrm{~m}^{2}$ and no rescue therapy. Prevalence and predictive factors of CRR and PERR at 12 and 24 months after Belimumab initiation were analyzed by multivariate logistic regression analysis.

Results: A total of 91 patients were considered in this study, 79 female, mean age $40.51 \pm 9.03$ years, mean disease duration $12.18 \pm 8.15$ years, median follow-up time after Belimumab initiation 22 months. Twenty patients had baseline proteinuria $\geq 0.5<1 \mathrm{~g} /$ day, $17 \geq 1<2 \mathrm{~g} /$ day, $13 \geq 2 \mathrm{~g} /$ day. Belimumab was started at GN onset in $20(22 \%)$ patients and at the time of a renal flare in all other cases. Seventy-five patients underwent a renal biopsy: 1 class I, 4 class II, 14 
class III, 47 class IV and 9 class V. Baseline serum creatinine was $82.44 \pm 29.26$ umol/L; 15 patients showed eGFR $<60 \mathrm{ml} / \mathrm{min} / 1.73 \mathrm{~m}^{2}$ at baseline. Immunosuppresants were taken by 70 (76.9\%) patients: 47 micofenolate, 15 azathioprine and 5 ciclosporine. Sixty patients $(65.9 \%)$ were on antimalarials. During follow-up $34(37.4 \%)$ patients achieved CRR. Among them $5(14.7 \%)$ patients relapsed and $29(85.3 \%)$ patients maintained remission. Mean time to achieved CRR was $9.71 \pm 5.91$ months

High levels of baseline proteinuria were a negative independent predictor of CRR and PERR at 6 months (OR $0.044 \mathrm{Cl} 95 \%$ 0.006-0.320 $p=0.002$ and OR 0.232 CI95\% 0.091-0.596 $p=0.002$ ) and 12 months (OR $0.029 \mathrm{Cl} 95 \%$ 0.002-0.556 $p=0.019$ and OR $0.056 \mathrm{CI} 95 \% 0.009-0.327 p=0.001)$. High levels of baseline creatinine were a negative independent predictor of renal response. Renal response at 6 months was a strong predictive factor of renal response at 12 and 24 months. Conclusion: Belimumab is an effective add-on therapy in the treatment of GN in real-life practice setting.

Disclosure of Interests: None declared

DOI: 10.1136/annrheumdis-2021-eular.1757

\section{POS0694 REAL-WORLD ECONOMIC IMPLICATIONS OF ACHIEVING LOW DISEASE ACTIVITY IN LUPUS NEPHRITIS}

M. Dall'era ${ }^{1}$, T. Hermes ${ }^{2}$, M. Eaddy ${ }^{3}$, A. Ogbonnaya ${ }^{3}$, E. Farrelly ${ }^{3}$, P. MinaOsorio ${ }^{4} .{ }^{1}$ UCSF, Rheumatology, San Francisco, United States of America; ${ }^{2}$ Aurinia Pharmaceuticals Inc., Commercial, Rockville, United States of America; ${ }^{3}$ Xcenda, Health Economics, Carrollton, United States of America; ${ }^{4}$ Aurinia Pharmaceuticals Inc., Medical Affairs, Victoria, Canada

Background: Lupus nephritis (LN) is a common and severe manifestation of systemic lupus erythematosus (SLE) affecting $50 \%$ of SLE patients and leading to end-stage kidney disease (ESKD) in up to $30 \%$ of patients with LN. ${ }^{1}$ Previous studies have reported higher healthcare costs in patients with SLE that develop LN compared to patients without $L N{ }^{2-5}$ These studies captured overall treatment costs associated with LN, regardless of disease activity or severity, and were conducted in small patient populations.

Objectives: The aim of this study was to assess the real-world economic implications of achieving low disease activity compared to active disease or ESKD in a large LN population.

Methods: This study was a retrospective observational analysis of patients with LN within Optum's health plan identified with ICD9 or ICD10 codes to have LN between January 1, 2015, and December 31, 2019. Patients were $\geq 18$ years of age and had $\geq 2$ months of follow-up data available. Patients were followed until death, loss to follow-up, or December 31, 2019. Low disease activity was defined by evidence of glucocorticoid doses $\leq 5 \mathrm{mg} /$ day, evidence of mycophenolate mofetil (MMF) doses $\leq 2 \mathrm{~g} /$ day, and no use of cyclophosphamide for $\geq 6$ consecutive months. Follow-up time that could not be defined as low disease activity was defined as active disease periods, except for periods with evidence of ESKD. Healthcare payer costs for medical and pharmacy services were compared between periods of low disease activity, active disease, and ESKD. A univariate generalized estimating equation model accounting for interdependence was used to compare differences in costs between periods of active and low disease activity.

Results: A total of 21,251 patients with LN met study criteria with a mean follow-up time of 31.0 months. The mean age was 60.3 years; $86.9 \%$ of patients were female and $35.2 \%$ of patients were non-White race. Low disease activity was evident in $51.3 \%$ of patients with a mean duration of 27.5 months. Mean monthly medical costs were $\$ 2,523$ during periods of low disease activity and $\$ 4,777$ during periods of active disease. After factoring in pharmacy costs, mean monthly total costs were $\$ 3,584$ during periods of low activity and $\$ 6,612$ during periods of active disease $(P<0.001)$. The mean monthly costs of ESRD were $\$ 18,084$ for medical and $\$ 3,760$ for pharmacy.

Conclusion: Achieving low disease activity in patients with LN is associated with reduced economic burden to healthcare payers, with monthly medical costs averaging $\$ 2,254$ less and total monthly costs averaging $\$ 3,028$ less than costs during periods of active disease.

\section{REFERENCES}

[1] Parikh SV et al. Update on Lupus Nephritis: Core Curriculum 2020. Am J Kidney Dis. 2020;76(2):265-281.

[2] Bartels-Peculis $L$ et al. Treatment patterns and health care costs of lupus nephritis in a United States payer population. Open Access Rheumatol. 2020;12:117-124
[3] Furst DE et al. Medical costs and healthcare resource use in patients with lupus nephritis and neuropsychiatric lupus in an insured population. J Med Econ. 2013;16(4):500-509.

[4] $\mathrm{Li} \mathrm{T}$ et al. Long-term medical costs and resource utilization in systemic lupus erythematosus and lupus nephritis: a five-year analysis of a large Medicaid population. Arthritis Rheum. 2009;61(6):755-763.

[5] Pelletier EM et al. Economic outcomes in patients diagnosed with sys temic lupus erythematosus with versus without nephritis: results from an analysis of data from a US claims database. Clin Ther. 2009;31(11): 2653-2664.

Disclosure of Interests: Maria Dall'Era Speakers bureau: Consulting agreement with Aurinia for Advisory Boards and educational lectures, Tim Hermes Shareholder of: Aurinia Pharmaceuticals Inc., Employee of: Aurinia Pharmaceuticals Inc., Michael Eaddy Consultant of: Aurinia Pharmaceuticals Inc., Augustina Ogbonnaya Consultant of: Aurinia Pharmaceuticals Inc., Eileen Farrelly Consultant of: Aurinia Pharmaceuticals Inc., Paola Mina-Osorio Shareholder of: Aurinia Pharmaceuticals Inc., Employee of: Aurinia Pharmaceuticals Inc.

DOI: 10.1136/annrheumdis-2021-eular.1928

\section{POS0695 INHIBITOR FOR THE TREATMENT OF SYSTEMIC LUPUS ERYTHEMATOSUS: RESULTS FROM THE COMPLETED DOSE ESCALATION PHASE 1B PORTION OF THE MISSION STUDY}

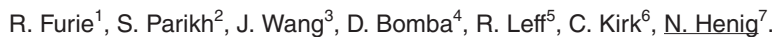
${ }^{1}$ Northwell Health, Chief, Division of Rheumatology, Great Neck, United States of America; ${ }^{2}$ Ohio State University Wexner Medical Center, Division of Nephrology, Columbus, United States of America; ${ }^{3}$ Kezar Life Sciences, Drug Metabolism, South San Francisco, United States of America; ${ }^{4}$ Kezar Life Sciences, Clinical Operations, South San Francisco, United States of America; ${ }^{5}$ Kezar Life Sciences, Clinical Science, South San Francisco, United States of America; ${ }^{6}$ Kezar Life Sciences, Chief Science Officer, South San Francisco, United States of America; ${ }^{7}$ Kezar Life Sciences, Chief Medical Officer, South San Francisco, United States of America

Background: KZR-616 is a first-in-class selective inhibitor of the immunoproteasome, which is active in $>15$ autoimmune disease models, including murine models of systemic lupus erythematosus (SLE)/lupus nephritis (LN). ${ }^{1,2,3}$ Selective inhibition of the immunoproteasome modulates both innate and adaptive immune effector cells, resulting in reduced inflammatory $T$ helper cell subsets (Th1 and Th17), increased regulatory T cells, and decreased plasma cells and autoantibodies. KZR-616 was well tolerated in two healthy volunteer studies of 100 subjects receiving up to $75 \mathrm{mg}$ subcutaneously (SC). Target levels of immunoproteasome inhibition were observed at doses $\geq 30 \mathrm{mg}^{3,4} \mathrm{KZR}-616$ is currently in Phase 2 studies for several autoimmune indications, including the ongoing Phase 2 portion of the MISSION Study (KZR-616-002; NCT0339013) in patients with LN.

Objectives: Results of the completed MISSION Phase $1 \mathrm{~b}$ dose escalation por tion of the study are reported.

Methods: In the open-label, multicenter, dose escalation Phase 1b portion, SLE patients (per SLICC Classification Criteria) with SLEDAI $\geq 4$ despite stable background immunosuppressant, anti-malarial, and/or corticosteroid therapy were administered weekly KZR-616 subcutaneously at doses of $45 \mathrm{mg}$ (cohort 1), $60 \mathrm{mg}$ (cohort 2), $60 \mathrm{mg}$ following step-up doses of $30 \mathrm{mg}$ and $45 \mathrm{mg}$ (cohort 2a), $60 \mathrm{mg}$ following a step-up dose of $30 \mathrm{mg}$ (cohorts $2 \mathrm{~b}, 2 \mathrm{c}$ ) or $75 \mathrm{mg}$ following a step-up dose of $30 \mathrm{mg}$ (cohort 3 ) for 13 weeks with follow-up through Week 25 (W25); a lyophilized formulation was used for cohorts $2 \mathrm{~b}, 2 \mathrm{c}$ and 3 . The disease activity measures assessed were: SLEDAI-2K, Cutaneous Lupus Erythematosus Disease Area and Severity Index (CLASI), 28 tender and swollen joint counts, Physician and Patient Global Assessments, and Patient Assessment of Pain. Safety and tolerability were assessed in the safety population (patients receiving at least one dose of KZR-616).

Results: The Phase 1b portion of MISSION enrolled 47 SLE patients, including 2 patients with active proliferative LN. The most common treatment-emergent adverse events (TEAE) were injection site reactions, which were mostly mild. Infections occurred at a low rate, and there were no reports of peripheral neuropathy, prolonged hematologic AEs, or clinically significant laboratory abnormalities. No discontinuations were observed in cohorts $2 \mathrm{~b}$ and $2 \mathrm{c}$; no serious AEs were reported in cohort 3 and TEAEs were consistent with those reported in earlier cohorts. Mean values of all measures of disease activity improved in evaluable patients who completed the 13-week treatment period, and improvements were generally maintained at W25. All patients with 